\title{
Home-based neonatal care by Health Extension Worker in rural Sidama Zone southern Ethiopia: a cross-sectional study
}

This article was published in the following Dove Press journal:

Pediatric Health, Medicine and Therapeutics

\author{
Achamyelesh Gebretsadik' \\ Akalewoled Alemayehu' \\ Million Teshome ${ }^{2}$ \\ Mekdes Mekonnen ${ }^{3}$ \\ Yusuf Haji \\ 'School of Public Health, Hawassa \\ University, Hawassa, Ethiopia; \\ ${ }^{2}$ Department of Obstetrics, School \\ of Medicine, Hawassa University, \\ Hawassa, Ethiopia; ${ }^{3}$ School of Nursing, \\ Hawassa University, Hawassa, Ethiopia
}

Correspondence: Achamyelesh Gebretsadik

School of Public Health, Hawassa University, PO Box 46, Hawassa, Ethiopia

Tel +251911303128

Email agtsadik@gmail.com
Background: Home-based neonatal care is associated with a reduction in neonatal mortality in settings with poor access to health facility-based care. The first day of a child's life is a day of unparalleled opportunity to spare lives and sets the level for a sound future. The aim of this study was to evaluate the prevalence and timing of home-based neonatal care by health extension workers (HEWs) in the rural Sidama Zone of southern Ethiopia.

Subjects and methods: A community-based, cross-sectional study was conducted, and a total of 2,040 mothers who had a live birth in the last 6 months were studied from 1 to 31 January 2017. Interviewer-administered data were collected using a standard questionnaire developed by the Saving Newborn Lives Program. A descriptive analysis and logistic regression analyses were done.

Results: It was found that 252/2,040 (12.4\%) mothers and their neonates were visited by the HEWs during the first month of birth. Out of all households who had a history of visits, 139 (55.2\%) had a single visit. Of these, only 66/252 (26.2\%) of the first visit were within the first 24 hours. Mothers who received postnatal home visit by the HEWs were at 1.35 times greater odds to have good postnatal practice compared to unvisited mothers (adjusted odds ratio [AOR] 1.35, 95\% CI $[1,1.71])$. Mothers who gave their last birth at home were $36 \%$ less likely to have good postnatal practice compared to those who gave birth in a health institution (AOR $0.64,95 \% \mathrm{CI}[0.53,0.79]$ ). Conclusion: Majority of the neonates did not get the recommended number and frequency of home visits. Postnatal home visit by HEWs had a great role in mothers having good postnatal practice. Therefore, all stakeholders should give attention on strengthening supportive supervision, proper implementation of community-based maternal and neonatal care is very crucial. Keywords: home-based neonatal care, health extension worker, rural Sidama, Ethiopia

\section{Background}

Globally, 2.6 million babies die every year in their first months of life, with almost all of these deaths occurring in middle- and low-income countries. ${ }^{1}$ According to the Ethiopia Demographic and Health Survey Report 2016, the neonatal mortality rate was 29 deaths per 1,000 live births. ${ }^{2}$ Preterm birth, intrapartum-related complications (birth asphyxia or lack of breathing at birth) and infections cause most neonatal deaths. More than half of these early child deaths are due to conditions that could be prevented or treated with access to simple, affordable interventions. ${ }^{1}$

The first day of life is the most dangerous day for both mothers and babies worldwide, as well as a day of unequaled opportunity to save lives and set the stage for a healthy future. ${ }^{3}$ Approximately $71 \%$ of neonatal deaths occur within the first week 
after birth, with the cumulative death rate reaching $79 \%$ in the second week. ${ }^{4,5}$ Home-based neonatal care is associated with a reduction in neonatal and perinatal mortality in settings with high neonatal mortality rates and poor access to health facility-based care. ${ }^{6-10}$ There is widespread consensus on the central role that community health workers can play in ending preventable maternal, newborn and child deaths. ${ }^{8,11}$

An immediate postnatal home visit, within 24 hours, a second visit on the third day and, if possible, a third visit on day 7 by the health extension workers (HEWs) help to reduce neonatal deaths and improve maternal and neonatal health. ${ }^{12}$ HEWs was basically designed to give basic maternal care and improve the health of the mothers during the antenatal delivery and postnatal period. Postnatal home visiting by the HEWs includes assessing both mother's and neonate's general physical examination and vital signs; checking cord; checking for danger signs such as any bleeding, convulsion, breathing problems, any health problems; counseling about breastfeeding, skin to skin contacts; and providing health education based on mother's health status. ${ }^{13}$ Lacking contact with them means lacking basic essential care at this critical period. As a result, it leads to poor postnatal practice by the mothers, such as failure to practice exclusive breastfeeding, throwing away the first breast milk which is very crucial to protect the neonate from a number of infectious diseases, poor maternal knowledge of danger signs and not seeking care for sick neonates. Therefore, it contributes to mortality and morbidity for the mothers and neonates. ${ }^{14,15}$ Evidence has also shown that community-based home care by the community health workers on the first day of life increases the survival rate of both the mothers and their neonates. ${ }^{11}$

Ethiopia has demonstrated that basic health services can be made accessible to a large proportion of the population through the government-led, cost-effective, community-based health delivery platform. Building on the government flagship health extension program at the community level, priority was given to the scale-up of community-based newborn and child survival interventions through HEWs and Health Development Army (HDA). ${ }^{16}$

In addition, when the Ethiopian Federal Ministry of Health launched the innovative community-based neonatal care (CBNC) strategy in 2012 for the implementation of a Sustainable Development Goal, this innovative strategy was designed to improve maternal and neonatal health. ${ }^{13}$ The aim of the CBNC program was to improve the survival of newborns through the Integration of Community Case Management. ${ }^{13}$ The core principle of the CBNC strategy is to ensure the continuum of care, that is, from pregnancy to postnatal periods, as well as from the home/community to the health facilities. This allows for the provision of skilled care during pregnancy, childbirth and postnatal periods and enables the early detection and appropriate management of problems, which will prevent complications. In such a way, the CBNC will improve maternal and newborn care practices and care-seeking through HDAs and other effective community mobilization mechanisms. ${ }^{17}$

In the Southern Nation Nationalities People Region, a number of packages of interventions target newborn care. The health extension program is highly essential in delivering quality maternal, neonatal and child health services through efficient and effective linkages between health centers, health posts and the community. ${ }^{16}$

The CBNC program was implemented 4 years back in the region; however, few studies have been done to show the progress of its implementation. Consequently, the aim of this study was to measure the prevalence and timing of homebased neonatal care by HEWs in the rural Sidama Zone of southern Ethiopia.

\section{Subjects and methods Study setting}

The study was conducted in five districts of the Sidama Zone, namely, Shebadino, Boricha, Wonsho, Dale and Loka Abaya. This zone is located in the northeastern part of the Southern Nation Nationalities People Region. Hawassa City, which is located at $274 \mathrm{~km}$ south of Addis Ababa, is both the regional and zonal headquarters. The zone's geographic location lies between $6^{\circ} 14^{\prime}$ and $7^{\circ} 18^{\prime}$ north latitude and $37^{\circ} 92^{\prime}$ and $39^{\circ} 14^{\prime}$ east longitude, with the total area being $\sim 6,981.8 \mathrm{~km}^{2}$. The zone mainly produces "enset", wheat, teff and barley as crops and cereals and coffee as cash crops. These districts had a total population of 1,099,345 (50.3\% male and $49.7 \%$ female) in 2015-2016 as projected based on the 2007 National Census, with the total households estimated at $162,919 .{ }^{18}$ The district has a total of 148 kebeles (the smallest administrative units), whereas the estimated eligible mothers with children aged 1-6 months in the study area is 34,075 . The study area has one district hospital, 42 health centers and 147 health posts. The common health problems of these districts are pneumonia, followed by neonatal infections. ${ }^{19}$

\section{Source population}

The primary source population was mothers who had given birth to a live baby in the last 6 months (from 29 days to 6 months) and were residing in the study districts. 


\section{Study population}

The study population consisted of all mothers who gave birth to a live child in the past 6 months (from 29 days to 6 months) and were residing in the selected cluster woreda/kebele.

\section{Study design}

A community-based, cross-sectional survey was conducted among mothers who had a live birth in the past 6 months and had babies aged at least 1 month at the time of the home visit.

\section{Sample size and sampling techniques}

The study employed a two-stage cluster sampling at the woreda and kebele level. Five districts were purposively selected out of 21 districts existing in the zone, considering their health burden. The selected districts have 148 kebeles, of which Boricha has 39, Dale 35, Shebadino 32, Loka Abaya 26 and Wonsho 16. Out of 148 kebeles, 30 were selected using randomly generated numbers with open Epi software, accounting for $20 \%$ of the total, and their distribution was as follows: Boricha (8), Dale (7), Shebedino (7), Loka Abaya (5) and Wonsho (3). The overall estimated number of mothers with 1-6-month old infants was 2,090 from all 30 kebeles. Therefore, all the eligible mothers of 1-6-month old infants within the selected clusters were included in the study.

\section{Inclusion criteria}

The inclusion criteria were all 15-49-year old mothers with infants aged 1-6 months, who were residing in the study area for at least 12 months, while mothers with stillbirths and mothers who resided in the study area for $<6$ months were excluded. The age of the infants was based on the mothers' report and was cross-checked from the immunization card.

\section{Data collection}

We adopted a standard questionnaire developed by the Saving Newborn Lives Program, with a few modifications for this survey. Data were collected between 1 and 31 January 2017 by five teams of four interviewers and one supervisor. All data collectors and supervisors were selected using their previous experience in data collection, local language ability and being a nurse/midwife/health officer by profession. Prior to the start of data collection, 2 days of training was provided by the investigators for the data collectors and supervisors to orient and familiarize the teams with the study objectives and tools. Following the household screening and selection procedures, the interviewers visited each eligible woman at her home to administer the survey.

\section{Variables}

The variables were respondent and household characteristics, home-based neonatal care by HEWs, time of visit and types of neonatal care.

\section{Data quality control}

A data management manual detailing all field data collection procedures, storage and entry was developed for the field staff, and a pretest was conducted in the nearby districts with the same community characteristics and discussion held to improve the data collection tools. During the collection time, data editors checked all the completed questionnaires for errors and missing information. Each supervisor re-interviewed five respondents every day in order to check the consistency of the information being collected. A supportive follow-up was also done by all the investigators. Of the total $10 \%$, double data entry was done to ensure the quality of the data.

\section{Data entry, analyses and processing}

The collected data were entered using the EpiData 3.1 software. As one way of checking for the consistency of data entry, double entries of the data were done for $10 \%$ of the questionnaires. The EpiData data set was checked and the data were transferred to SPSS; descriptive data and a logistic regression analysis were also used to assess the risks of neonatal outcomes among HEWs that had postnatal home visits and those that were not visited, with a $95 \% \mathrm{CI}$ and $P$-value $<0.05$ taken as the level of significance.

\section{Operational definitions}

Postnatal home visits by HEWs: the HEWs are expected to make postnatal home visits on days 1,3 and 7 for all newborns, whereas those with special needs should also be visited on the 15 th day. ${ }^{13}$

Good postnatal practice is considered if a mother is exclusively breastfeeding, not throwing away the first breast milk, initiated breastfeeding within the first 1 hour after birth and has good knowledge of danger signs.

Poor postnatal practice is considered if a mother is not exclusively breastfeeding, had a history of throwing away the first breast milk, history of breastfeeding not initiated within the first 1 hour after birth and having poor knowledge of danger signs.

HEW: HEW is a cadre of government worker who received 1 year of training and is paid a government salary to deliver the health program at the community level in rural areas. $^{20}$ 
HDAs: they are similar to community health workers or a community volunteer and are not formally integrated within the health system.

\section{Ethical approval}

Proposal review and approval was given by the research and the ethics committee of the School of Public Health and the Institutional Review Board of the College of Medical and Health Sciences at Hawassa University. Permission to undertake this study was obtained from every relevant authority of all the selected district health offices. Oral informed consent was also directly obtained from all participants, including those under the age of 18 years. It was accepted and approved by the Institutional Review Board of the College of Medical and Health Sciences at Hawassa University. The informed consent included information on potential risk, benefits and confidentiality. Furthermore, informed consent was aligned with the ethical principle of "autonomy" by including information that gave participants the right to decline participation and to withdraw at any time. The data collectors were given health education on how to refer to nearby health facilities if any sick neonate is identified at the time of data collection.

\section{Results}

\section{Sociodemographic characteristics}

Data were collected from about 2,040 samples, thus making the response rate $98.1 \%$. Out of 2,040 samples from various woredas, 547 (26.8\%) were from Boricha, 547 (26.8\%) from Dalle, 559 (27.4\%) from Shebedino, 187 (9.2\%) from Loka Abaya and the remaining 200 (9.8\%) were from Wonsho.

The majority of the mothers, $699(34.3 \%)$, were in the age group from 20 to 24 . More than half of the mothers $(1,356$ [66.5\%]) had attended school, and among them, $606(44.7 \%)$ attained the eighth grade. Regarding marital status, nearly all $(2,010$ [98.5\%]) were married or living together, with most of the mothers $(1,736$ [85.1\%]) being housewives by occupation. The number of spouses who were illiterate was $690(33.8 \%)$, with those >grade 9 numbering $207(10.1 \%)$. Lastly, more than half $(1,206$ [59.1\%]) of the spouses were farmers (Table 1).

\section{Maternal postnatal practice}

Among all mothers, $899(44.6 \%)$ had a history of good postnatal practice, $439(21.5 \%)$ did not throw away the first breast milk and 499 (24.8\%) were exclusively breast feeding during the time of the survey. Also, 1,601 (78.1\%) of the mothers initiated breastfeeding within 1 hour of birth. Concerning the
Table I Sociodemographic characteristics of mothers and their neonates in the rural Sidama Zone, southern Ethiopia, 2017

\begin{tabular}{|c|c|c|}
\hline Variables $(N=2,040)$ & Frequency & Percentage \\
\hline \multicolumn{3}{|l|}{ Sex of the child } \\
\hline Male & I,057 & 51.8 \\
\hline Female & 983 & 48.2 \\
\hline \multicolumn{3}{|l|}{ Child's age in weeks } \\
\hline 4 & 130 & 6.4 \\
\hline $5-12$ & 598 & 29.3 \\
\hline $13-24$ & $1,3 \mid 2$ & 64.3 \\
\hline \multicolumn{3}{|l|}{ Mothers' age, years } \\
\hline $15-19$ & 203 & 10 \\
\hline $20-24$ & 699 & 34.3 \\
\hline $25-29$ & 598 & 29.3 \\
\hline $30-34$ & 350 & 17.2 \\
\hline$\geq 35$ & 190 & 9.3 \\
\hline \multicolumn{3}{|l|}{ Did the mother attend school? } \\
\hline Yes & $\mathrm{I}, 356$ & 66.5 \\
\hline No & 684 & 33.5 \\
\hline \multicolumn{3}{|l|}{$\begin{array}{l}\text { Highest grade attended by the } \\
\text { mother }(n=1,356)\end{array}$} \\
\hline Grade I-4 & 543 & 40 \\
\hline Grade 5-8 & 606 & 44.7 \\
\hline Grade 9-10 & 147 & 10.8 \\
\hline Higher than grade 10 & 60 & 4.5 \\
\hline \multicolumn{3}{|l|}{ Maternal occupation } \\
\hline Housewife & 1,736 & 85.1 \\
\hline Merchants/traders & 150 & 7.4 \\
\hline Daily laborer and others & 66 & 3.2 \\
\hline Farmer & 88 & 4.3 \\
\hline \multicolumn{3}{|l|}{ Spouse's main occupation } \\
\hline Farmer & 1,206 & 59.1 \\
\hline Merchant/trader & 574 & 28.1 \\
\hline Day laborer/other & 164 & 8.7 \\
\hline Employed & 84 & 4.1 \\
\hline \multicolumn{3}{|l|}{ Place of delivery } \\
\hline Health facilities & 1,469 & 72 \\
\hline Home & 571 & 28 \\
\hline
\end{tabular}

neonatal experience of illness, $226(11.1 \%)$ of the children suffered from any illness during the first months of life.

\section{Postnatal home visit by HEWs}

Of the total sampled households, 252/2,040 (12.4\%) of mothers and their neonates were visited by the community health workers during the postnatal period. Out of these households, almost all were visited by HEWs (252/2,040 [12.4\%]). More than half of the households had a history of visits, 141 (56\%) were visited once, $81(32.1 \%)$ were visited twice and 30 (11.9\%) households were visited three times by the HEWs. During the visit, 229/252 (90.9\%) of both mothers and their neonates were checked by HEWs at least once. Among all the households visited by HEWs, 66/141(46.8\%) of the first visit were within the first 24 hours, $46 / 81$ (56.7\%) of the second 
visit were within 72 hours and $21 / 30(70 \%)$ of the third visit were within 1 week after birth (Table 2).

During the first visit, general assessment was done in $231(91.7 \%)$ neonates by HEWs, $216(85.7 \%)$ mothers were

Table 2 Postnatal home visit for mothers and their neonates by HEW in rural Sidama zone, SNNPR, Ethiopia, 2017

\begin{tabular}{|c|c|c|}
\hline \multicolumn{2}{|c|}{$\begin{array}{l}\text { Mothers visited at home by any health worker } \\
\text { during the postnatal period }(\mathrm{N}=2,040)\end{array}$} & \multirow{2}{*}{\begin{tabular}{|l|}
$\%$ \\
12.9 \\
\end{tabular}} \\
\hline Yes & 263 & \\
\hline No & $\mathrm{I}, 777$ & 87.1 \\
\hline $\begin{array}{l}\text { HEW visited the home of the mother in the } \\
\text { postnatal period }(\mathrm{N}=2,040)\end{array}$ & & \\
\hline Yes & 252 & 12.4 \\
\hline No & $\mathrm{I}, 788$ & 87.6 \\
\hline Frequency of home visits by HEWs $(n=252)$ & & \\
\hline Once & $|4|$ & 56 \\
\hline Twice & 81 & 32.1 \\
\hline Three & 30 & 11.9 \\
\hline $\begin{array}{l}\text { Checkup was done by HEW during the } \\
\text { postnatal period }\end{array}$ & & \\
\hline Both mothers and their neonate $(n=252)$ & 229 & 90.9 \\
\hline Baby only? ( $n=252)$ & 15 & 5.9 \\
\hline Mother only? $(n=252)$ & 8 & 3.2 \\
\hline Time of first postnatal home visit by HEW & & \\
\hline Visited within 24 hours & 66 & 46.8 \\
\hline Visited in $2-3$ days & 38 & 26.9 \\
\hline Visited after 3 days & 37 & 26.3 \\
\hline $\begin{array}{l}\text { Time of second postnatal home visit by HEW } \\
(\mathrm{n}=8 \mathrm{I})\end{array}$ & & \\
\hline Within 72 hours & 46 & 26.2 \\
\hline$\geq$ Fourth day & 35 & 43.3 \\
\hline $\begin{array}{l}\text { Time of third postnatal home visit by HEW } \\
(n=30)\end{array}$ & & \\
\hline Within I week & 21 & 70 \\
\hline After I week & 9 & 30 \\
\hline
\end{tabular}

Abbreviations: HEW, Health Extension Worker; SNNPR, Southern Nation Nationalities People Region. counseled on breast feeding and $92(36.5 \%)$ of the babies were weighed (Table 3 ).

Regarding the assessment of mothers' knowledge of neonatal danger signs and symptoms which made the mother take their neonate right away to health facilities, $1,785(87.7 \%)$ mothers did so because of fever, $1,105(54.3 \%)$ for lethargy, $1,098(53.9 \%)$ for convulsions and 1,008 (49.5\%) if the baby felt cold. Overall, $51 \%$ of mothers were able to respond to five or more danger signs out of a list of eleven (Figure 1).

\section{Factors associated with postnatal practice}

Mothers who received postnatal home visit by HEWs were at 1.35 times greater odds to have good postnatal practice compared to unvisited mothers (adjusted odds ratio [AOR] $1.35,95 \% \mathrm{CI}[1,1.71])$. Mothers who had their last delivery at home were $36 \%$ less likely to have good postnatal practice compared to those who gave birth in a health institution (AOR $0.64,95 \%$ CI $[0.53,0.79])$. Those whose monthly income was below 1,500 ETB were $32 \%$ less likely to have good postnatal practice compared to those with a monthly income $\geq 2,000$ Birr (AOR 0.68, 95\% CI [0.48, 0.95]), as shown in Table 4.

\section{Discussion}

In this study, 252 (12.4\%) mothers received home-based care by HEWs. Among those who had a history of visits, $141 / 252$ neonates were visited at least once and $81 / 252$ were visited twice. During the time of the visit, 229/252 mothers and their neonates were visited. Among those who were visited by HEWs, only 66/252 received an appropriate visit within the critical time, that is, the first 24 hours. The type of care given during the home visit by the HEWs was as

Table 3 Types of maternal and neonatal care done during home visits by HEWs in postnatal period in rural Sidama Zone, SNNPR, 2017

\begin{tabular}{|c|c|c|c|}
\hline List of activities & $\begin{array}{l}\text { Visit I } \\
\text { Frequency and their (\%) }\end{array}$ & Visit 2 & Visit 3 \\
\hline The proportion of neonates that underwent body examination by HEWs & $231(91.7)$ & $109(96.5)$ & $29(96.7)$ \\
\hline The proportion of mothers counseled on breastfeeding & $216(85.7)$ & $99(87.6)$ & $26(87.6)$ \\
\hline The proportion of mothers checked for cord care & $210(83.3)$ & $101(89.4)$ & $27(90)$ \\
\hline The proportion of neonates observed for breastfeeding & $200(79.4)$ & $99(87.6)$ & $26(86.7)$ \\
\hline The proportion of babies checked for danger signs & $177(70.2)$ & $78(69)$ & $21(70)$ \\
\hline The proportion of mothers counseled on skin to skin contact & $145(57.5)$ & $73(64.6)$ & $21(70)$ \\
\hline The proportion of neonates observed in KMC position & $102(40.5)$ & $52(46)$ & $16(53.3)$ \\
\hline The proportion of neonates weighed & $92(36.5)$ & $51(45.1)$ & $17(56.7)$ \\
\hline The proportion of mothers counseled on danger signs & $82(32.5)$ & $45(39.8)$ & $16(53.3)$ \\
\hline The proportion of neonates referred to health center/hospital & $16(6.3)$ & $13(11.5)$ & $8(26.7)$ \\
\hline The proportion of mothers checked for nothing & $4(1.6)$ & $3(2.7)$ & 0 \\
\hline
\end{tabular}

Abbreviations: HEW, Health Extension Worker; KMC, kangaroo mother care; SNNPR, Southern Nation Nationalities People Region. 
follows: $88.3 \%$ of the neonates were checked for cord care, $79.4 \%$ were observed for breastfeeding, $32.5 \%$ of the mothers were counseled on danger signs, $36.5 \%$ of the neonates were weighed and $57.5 \%$ of the mothers were counseled on skin to skin contact. Regarding the knowledge of mothers on neonatal danger signs, $44.4 \%$ responded five or more times. Overall $45.6 \%$ of the postnatal mothers exhibited good practice. Postnatal home visit by the HEWs, place of delivery and monthly income showed significant association with good postnatal practice by the mothers.

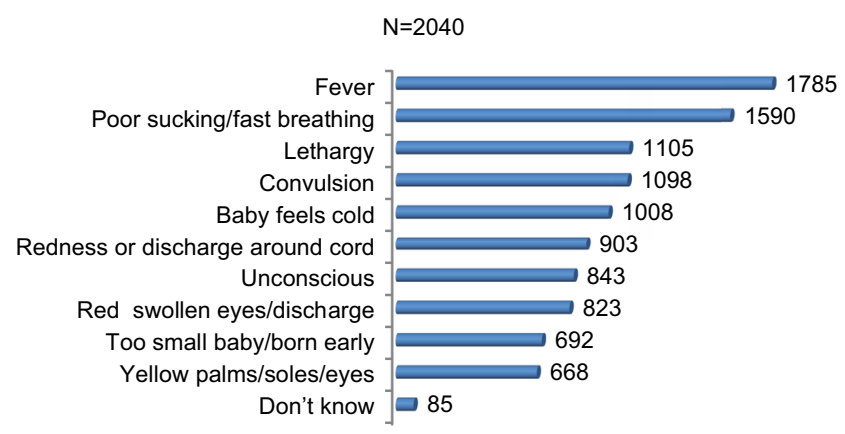

Figure I Maternal knowledge of neonatal danger signs and symptoms which caused them to take their neonate right away to a health facility in the rural Sidama Zone, SNNPR, Ethiopia, 2017.

Abbreviation: SNNPR, Southern Nation Nationalities People Region.
The study found that $12.4 \%$ of the neonates received home-based care from HEWs. Although there is a limited amount of literature to compare this study result, the result is in agreement with a study done in four regions of Ethiopia. ${ }^{21}$ However, it is very low compared to other studies done in Mali and Ethiopia. ${ }^{22,23}$ This might be as a result of the involvement of the HEWs in different activities. ${ }^{24}$ The HEW program was initially designed for later preventive care on curative activities, such as treating pneumonia, diarrhea and so on, and cases were added, making them much busier than before. ${ }^{24,25}$ Most of the HEWs not living in their duty station area instead come from nearby towns, so they do not work full time. ${ }^{25}$

Home visits for essential newborn care by trained HEWs on the first day of life reduce the risk of morbidity and mortality by more than two-thirds..$^{4,5,26,27}$ In this study, the proportion of neonates who received care from HEWs on the first day of life was $26.2 \%$, which is very low compared to another study done in Bangladesh. ${ }^{26}$ This might be due to the HEWs being very busy with other competing activities, ${ }^{28}$ as well as other reasons that need a further qualitative study.

The importance of home visits by HEWs is mainly to make essential newborn care accessible for those delivered at home. ${ }^{11,13,29}$ The primary causes of death during the

Table 4 Factors associated with postnatal practice in the rural Sidama zone, SNNPR, Ethiopia, 2017

\begin{tabular}{|c|c|c|c|c|c|c|}
\hline \multicolumn{2}{|l|}{ Variables } & \multicolumn{3}{|c|}{ Postnatal practice } & \multirow[t]{2}{*}{ AOR $95 \% \mathrm{Cl}$} & \multirow[t]{2}{*}{$P$-value } \\
\hline & & Good & Poor & COR 95\% CI & & \\
\hline \multirow[t]{5}{*}{ Maternal education } & Not applicable & $289(43.9)$ & $370(56.1)$ & 1 & 1 & \\
\hline & Grade I-4 & $240(44.9)$ & $294(55.1)$ & I.I (0.83, I.3I) & I.I $(0.83$, I.33) & $>0.05$ \\
\hline & Grade 5-8 & $27 \mid(44.7)$ & $335(55.3)$ & I.I (0.82, I.28) & I.I (0.82, I.29) & \\
\hline & Grade 9-10 & $69(43.7)$ & $89(56.3)$ & I $(0.69, \mid .42)$ & I $(0.69$, I.4) & \\
\hline & Higher than grade 10 & $30(5 \mid .7)$ & $28(48.3)$ & $\mathrm{I} .4(0.8 \mathrm{I}, 2.3)$ & I.4 $(0.8 \mathrm{I}, 2.4)$ & \\
\hline \multirow{4}{*}{$\begin{array}{l}\text { Occupation of } \\
\text { spouse }\end{array}$} & Farmer & $533(44.6)$ & $663(55.4)$ & I & I & $>0.05$ \\
\hline & Merchant/trader & $246(43.4)$ & $321(56.6)$ & I $(0.78,1.16)$ & I $(0.77,1.17)$ & \\
\hline & Day laborer/other & $72(45.9)$ & $85(54.1)$ & I.I (0.75, I.47) & I.I $(0.75$, I.48) & \\
\hline & Employed & $48(50.5)$ & $47(49.5)$ & $1.27(0.83,1.9)$ & I.I (0.7I, I.7) & \\
\hline \multirow[t]{5}{*}{ Income categorized } & $\leq 499$ ETB & $280(49)$ & $292(5 \mathrm{I})$ & I $(0.73$, I.29) & I $(0.77$, I.4) & \\
\hline & 500-999 ЕTВ & $295(41.8)$ & $4 I I(58.2)$ & $0.73(0.56, \mathrm{I})^{*}$ & $0.79(0.59, \mathrm{I})^{*}$ & 0.00 \\
\hline & I,000-1,499 ETB & $115(38.1)$ & $187(61.9)$ & $0.62(0.45,0.87)$ & $0.68(0.48,0.95)^{*}$ & 0.00 \\
\hline & I,500-I,999 ЕТВ & $64(45.1)$ & $78(54.9)$ & $0.83(0.56,1.25)$ & $0.89(0.59,1.33)$ & \\
\hline & $\geq 2,000$ ETB & 145 (49.5) & $148(50.5)$ & I & I & \\
\hline Place of delivery of & Home delivery & $202(36.1)$ & 357 (63.9) & $0.6 \mathrm{I}(0.50,0.75)^{*}$ & $0.64(0.53,0.79)^{*}$ & 0.00 \\
\hline the last child & Health institutions/skilled delivery & 697 (47.9) & $759(52.1)$ & 1 & I & \\
\hline Postnatal home visit & Yes & $130(52.4)$ & $118(47.6)$ & $\mathrm{I} .43(\mathrm{I}, \mathrm{I} .86)^{*}$ & $1.35(\mathrm{I}, \mathrm{I} .7 \mathrm{I})^{*}$ & 0.05 \\
\hline by HEWs & No & $769(43.5)$ & $998(56.5)$ & 1 & 1 & 0.00 \\
\hline \multirow[t]{2}{*}{ Have radio } & Yes & $242(46.3)$ & $28 \mathrm{I}(53.7)$ & $\mathrm{I} . \mathrm{I}(0.89, \mathrm{I} .33)$ & I.I (0.87, I.32) & \\
\hline & No & $657(44.0)$ & $835(56.0)$ & 1 & I & \\
\hline Distance to health & $<$ I hour & $884(44.6)$ & $1,099(55.4)$ & $0.91(0.45,1.83)$ & $0.95(0.46,1.93)$ & \\
\hline facility & $>1$ hour & 15 (46.9) & $17(53.1)$ & I & I & \\
\hline
\end{tabular}

Note: $* p<0.005$.

Abbreviations: COR, crude odds ratio; HEW, Health Extension Worker; SNNPR, Southern Nation Nationalities People Region. 
neonatal period in our country are birth asphyxia, low birth weight, preterm birth and neonatal sepsis. The proportions of care for breastfeeding, cord care, counseling about danger signs, weighed neonates and skin to skin contact were low compared to those reported in studies done in Ethiopia and Uganda. $^{21,23,27,30}$

This could be due to a lack of attention toward the aim of this program by HEWs, in addition to other government bodies, which have a responsibility to monitor the implementation of the strategy proposed by the Ministry of Health.

Maternal knowledge of the danger signs of neonatal illness is very crucial for timely seeking of medical care, to adhere to good postnatal practice and to save the life of newborns. ${ }^{31}$ Postnatal counseling given for mothers about the neonatal danger signs is one of the expected activities of the HEWs at the time of postnatal visit. The proportion of mothers with knowledge of neonatal danger signs in this study was $51 \%$, which is low compared to a study done in Eastern Tigray, Ethiopia. ${ }^{32}$ This might possibly be explained by the HEWs not giving much time for teaching the mothers appropriately because of their fast-moving multiple tasks. ${ }^{24,28}$

The other reason could be that two HEWs were assigned in one kebele; as a result, the proportion of the community which needs different care and the number of assigned HEWs were not proportional. ${ }^{24,28,33}$ Another reason for this might be that this study was done in a rural area, with most of the mothers having a lower educational level.

This study also showed a high proportion of exclusive breastfeeding rate, timely initiation of breastfeeding and the utilization of colostrum (the first breast milk) by the neonates among the mothers and their neonates visited by HEWs compared to those who were not visited. The composite of these variables operationally taken as good postnatal practice accounted $45.6 \%$. These activities are one of the benefits expected from HEWs during postnatal home visits, as they prevent neonatal morbidity and mortality. ${ }^{16}$ This study also found that postnatal home visit by the HEWs played a statistically significant role for good postnatal practice. This is because those mothers visited by the HEWs were more likely to get advice to do so. This finding is also supported by different studies done in low- and middle-income countries. ${ }^{34-36}$

The study also found that, compared to those delivered at a health facility, those who gave birth at home were less likely to have good practice. This is because there is no appropriate person to give advice for the mother at home. In addition, relatives or family members are usually present at home at the time of delivery and they might give wrong advice like to throw away the first milk. This finding is also similar to studies done in Ethiopia and the Bareilly district. ${ }^{35,37,38}$

\section{Limitation of the study}

The result of this study was obtained only from the maternal report and not supported by observation and interviewing HEWs. Our samples were not adequate enough to be used to look at the differences in neonatal mortality between those visited vs not visited by HEWs. Therefore, further studies are needed.

\section{Conclusion}

The CBNC strategy is very important in reducing neonatal mortality. The implementer of this strategy is the HEWs. However, nearly $88 \%$ of the neonates did not receive a home visit. Even among those visited only a few of them were visited on the first day of life. Postnatal home visit by the HEWs and institutional delivery have a great role in forming good postnatal practice among mothers. However, good postnatal practice among women who gave birth at a health facility was low. Therefore, the government should give much attention on reducing the different tasks given to the HEWs, strengthening supportive supervision and following up to do the appropriate home visit based on the designed strategy. ${ }^{13,20}$ Further studies are needed to evaluate why HEWs that are currently being implemented are not reaching expected outcomes. Further research is needed to investigate why more than half of the women who gave birth at a health facility continue to have poor postnatal practice.

\section{Data sharing statement}

The data sets generated and/or analyzed during the current study are available and can be shared based on request.

\section{Acknowledgments}

The authors would like to thank Save the Children and the CHIRT project for providing a budget for this study; the Hawassa University, College of Medicine and Health Science for the opportunity and overall material support; and the Sidama Zone Health Bureau and the five Woreda Health Offices for their support in approving the study. The authors would also like to thank Dr Fistum Weldgebrieal for her constructive comments during first draft write-up. Lastly, the authors would like thank the data collectors and the study participants, without whom this study could not have been conducted.

\section{Author contributions}

$\mathrm{AG}$ and $\mathrm{YH}$ were involved in the conception and design of the study, data collection, data supervision, data processing, cleaning, analysis and interpretation of the results, and 
developing the manuscript. AA, MT and MM were involved in the conception and design of the study, data collection and data supervision. All authors contributed toward data analysis, drafting and revising the paper, gave final approval of the version to be published, and agree to be accountable for all aspects of the work.

\section{Disclosure}

The authors report no conflicts of interest in this work.

\section{References}

1. World Health Organization. Children: reducing mortality fact sheets. 2017. Available from: http://www.who.int/news-room/fact-sheets/detail/ children-reducing-mortality. Accessed July 13, 2018.

2. Central Statistical Agency (CSA) [Ethiopia] and ICF. 2016. Ethiopia Demographic and Health Survey: Key Indicators Report. Addis Ababa, Ethiopia, and Rockville, MD: CSA and ICF. 2016. Available from: https://www.usaid.gov/sites/default/files/documents/1860/Ethiopia $\% 20$ DHS\%202016\%20KIR\%20-\%20Final\%2010-17-2016.pdf. Accessed July 13, 2018.

3. Save the children. Ending Newborn Deaths Ensuring Every Baby Survives. 2014. Available from: https://www.savethechildren.net/newborns. Accessed July 13, 2018.

4. Negera W, Eshetu W. Risk factors of neonatal mortality in Ethiopia. Ethiop J Health Dev. 2013;27(3):192-199.

5. Bang AT, Bang RA, Reddy HM, Deshmukh MD, Baitule SB. Reduced incidence of neonatal morbidities: effect of home-based neonatal care in rural Gadchiroli, India. J Perinatol. 2005;25 Suppl 1:S51-S61.

6. Lassi ZS, Haider BA, Bhutta ZA. Community-based intervention packages for reducing maternal and neonatal morbidity and mortality and improving neonatal outcomes. Cochrane Database Syst Rev. 2010 (11):CD007754

7. Roberton T, Applegate J, Lefevre AE, et al. Initial experiences and innovations in supervising community health workers for maternal, newborn, and child health in Morogoro region, Tanzania. Hum Resour Health. 2015;13(19):19.

8. Zulfiqar AB, Gary LD, Babar SH, Rachel AH. Community-based interventions for improving perinatal and neonatal health outcomes in developing countries: a review of the evidence. Pediatrics. 2005;115(2).

9. Gogia S, Sachdev HP. Home-based neonatal care by community health workers for preventing mortality in neonates in low- and middle-income countries: a systematic review. J Perinatol. 2016;36(Suppl 1):S55-S73.

10. Gogia S, Sachdev HS, Siddhartha G, Harshpal SS. Home visits by community health workers to prevent neonatal deaths in developing countries: a systematic review. Bull World Health Organ. 2010;88(9):658-666.

11. Aboubaker S, Qazi S, Wolfheim C, Oyegoke A, Bahl R. Community health workers: a crucial role in newborn health care and survival. J Glob Health. 2014;4(2).

12. Trend in the Maternal \& Newborn Health Care Practices in L10K Areas. Findings from the Baseline, Midterm and Rapid Community Surveys. Addis Ababa: Ethiopia. December 2013. Available from: http://110k. jsi.com/Resources/Docs/TrendinMNHPracticesinL10KAreas_000.pdf. Accessed July 13, 2018.

13. Federal Ministry of Health Ethiopia. Community Based Newborn Care Implementation Guideline. February 2012.

14. Medhanyie A, Spigt M, Kifle Y, et al. The role of health extension workers in improving utilization of maternal health services in rural areas in Ethiopia: a cross sectional study. BMC Health Serv Res. 2012;12(352):352.

15. Jackson R, Tesfay FH, Godefay H, Gebrehiwot TG. Health extension workers' and mothers' attitudes to maternal health service utilization and acceptance in Adwa Woreda, Tigray Region, Ethiopia. PLoS One. 2016;11(3):e0150747.
16. Federal Ministry of Health Ethiopia, Maternal and Child Health Directorate. National Strategy for Newborn and Child Survival in Ethiopia. 2015. Available from: https://www.unicef.org/ethiopia/Child_Survival_Strategy.pdf. Accessed July 13, 2018.

17. 10k L. Community Based Newborn Care. 2014;2(4). Available form: 10k. jsi.com/Resources/Docs/NewsletterVol2No4.pdf. Accessed July 15, 2018.

18. CSA. The 2007 National Census Report for Ethiopia. Central Statistical Agency, Addis Ababa, Ethiopia. 2008. Available from: https://unstats. un.org/unsd/statcom/statcom_08_events/special\%20events/population_census/docs/presentation\%20at $\% 20$ Stat $\% 20$ Com-UN\%20Samia1. pdf. Accessed: July 20, 2018.

19. Finance and Economics Department, Socioeconomic data analysis and dissemination core process. Sidama Zone, Hawassa: Ethiopia. 2015. https://www.hawassafinance.com/files/2006_profile.pdf. Accessed July 12,2018 .

20. Federal Ministry of Health. Health Extension program in Ethiopia Health Extension and Education Center. Addis Ababa: Ethiopia. 2007. Available from: http://www.moh.gov.et/documents/20181/21665/Heal th+Extension+Program+in+Ethiopia.pdf/0c486437-71bf-485b-b6147e720dc924b6. Accessed July 13, 2018.

21. Callaghan-Koru JA, Seifu A, Tholandi M, et al. Newborn care practices at home and in health facilities in 4 regions of Ethiopia. BMC Pediatr. 2013;13(198):198.

22. Freddy P, Hamady B, Sayed GD, Mathias A. The role of community health workers in improving child health programs in Mali. BMC Int Health Hum Rights. 2009;9(28).

23. Karim AM, Admassu K, Schellenberg J, et al. Effect of Ethiopia's health extension program on maternal and newborn health care practices in 101 rural districts: a dose-response study. PLoS One. 2013;8(6): e65160.

24. Legesse H, Degefie T, Hiluf M. National scale-up of integrated community case management in rural Ethiopia: implementation and early lessons learned. Ethiop Med J. 2014;52 Suppl 3(3):15-26.

25. Mangham-Jefferies L, Mathewos B, Russell J, Bekele A. How do health extension workers in Ethiopia allocate their time? Hum Resour Health. 2014;12(61):61.

26. Abdullah HB. Effect of timing of first postnatal care home visit on neonatal mortality in Bangladesh: an observational cohort study. $B M J$. 2009;339(2826).

27. Bogale TN, Worku AG, Bikis GA, Kebede ZT. Why gone too soon? Examining social determinants of neonatal deaths in northwest Ethiopia using the three delay model approach. BMC Pediatr. 2017; 17(1):216

28. Federal Ministry of Health. Health Extension Workers Time. Motion Study Complemented by In-depth Interviews within Primary Health Care Units in Ethiopia. 2015. Available from: https://cdn1.sph.harvard.edu/wp-eMotion-Study-Report-HEPCAPS2-FINAL.pdf. Accessed July 13, 2018.

29. Deborah S, Tanya G, Peter W, Sarah N, Namazzi G et al. Improving newborn care practices through home visits: lessons from Malawi, Nepal, Bangladesh, and Uganda. Glob Health Action. 2015; 8(23963).

30. Owor MO, Matovu JKB, Murokora D, Wanyenze RK, Waiswa P. Factors associated with adoption of beneficial newborn care practices in rural Eastern Uganda: a cross-sectional study. BMC Pregnancy Childbirth. 2016;16(83):83.

31. Abdullah A, Hort K, Butu Y, Simpson L. Risk factors associated with neonatal deaths: a matched case-control study in Indonesia. Glob Health Action. 2016;9(30445):30445.

32. Misgna HG, Gebru HB, Birhanu MM, Haftu B. Knowledge, practice and associated factors of essential newborn care at home among mothers in Gulomekada District, Eastern Tigray, Ethiopia, 2014. BMC Pregnancy Childbirth. 2016;16(1):144.

33. Ruth J. Ethiopia has cracked the problem of rural health. But its workers feel stuck. The conversation. 2015 Nov 25.

34. Mirmolaei ST, Valizadeh MA, Mahmoodi M, Tavakol Z. Comparison of effects of home visits and routine postpartum care on the healthy behaviors of Iranian low-risk mothers. Int J Prev Med. 2014;5(1): $61-68$. 
35. Memon ZA, Khan GN, Soofi SB, Baig IY, Bhutta ZA. Impact of a community-based perinatal and newborn preventive care package on perinatal and neonatal mortality in a remote mountainous district in Northern Pakistan. BMC Pregnancy Childbirth. 2015;15(106):106.

36. Setegn T, Gerbaba M, Belachew T. Determinants of timely initiation of breastfeeding among mothers in Goba Woreda, South East Ethiopia: a cross sectional study. BMC Public Health. 2011;11(1):217.
37. Alebel A, Dejenu G, Mullu G, Abebe N, Gualu T, Eshetie S. Timely initiation of breastfeeding and its association with birth place in Ethiopia: a systematic review and meta-analysis. Int Breastfeed $J$. 2017;12:44.

38. Singh A, Gupta SB, Khan H. Early initiation of breastfeeding practice among institutional delivered women in district Bareilly. Int J Community Med Public Health. 2017;4(9).
Pediatric Health, Medicine and Therapeutics

\section{Publish your work in this journal}

Pediatric Health, Medicine and Therapeutics is an international, peerreviewed, open access journal publishing original research, reports, editorials, reviews and commentaries. All aspects of health maintenance, preventative measures and disease treatment interventions are addressed within the journal. Practitioners from all disciplines are invited to submit

\section{Dovepress}

their work as well as healthcare researchers and patient support groups. The manuscript management system is completely online and includes a very quick and fair peer-review system. Visit http://www.dovepress.com/ testimonials.php to read real quotes from published authors.

Submit your manuscript here: http://www.dovepress.com/pediatric-health-medicine-and-therapeutics-journal 